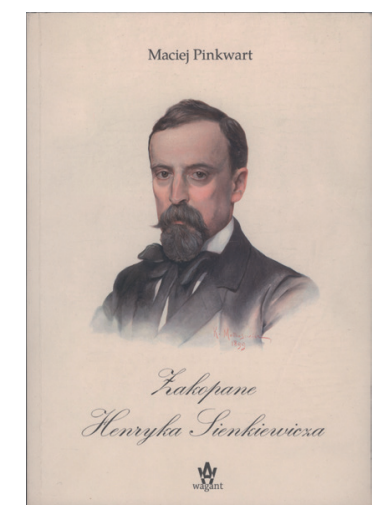

\title{
W Zakopanem śladami Henryka Sienkiewicza
}

DOl: 10.19195/2084-4107.11.35

[rec.:] Maciej Pinkwart, Zakopane Henryka Sienkiewicza, Wagant, Nowy Targ 2016, ss. 304.

In Zakopane, in the footsteps of Henryk Sienkiewicz

Słowa-klucze: Henryk Sienkiewicz, Zakopane, literatura, kultura, historia

Keywords: Henryk Sienkiewicz, Zakopane, literature, culture, history

Henryk Sienkiewicz - jako najlepiej rozpoznawalny i najchętniej cytowany polski pisarz oraz laureat Nagrody Nobla — nie mógłby narzekać na brak publikacji poświęconych zarówno swojej osobie, jak i twórczości. Po obchodzonym niedawno kolejnym roku jubileuszowym tych opracowań można odnaleźć jeszcze więcej, a wiedza o autorze Krzyżaków i jego dokonaniach została znacznie pogłębiona. W nurt wydań ,jubileuszowych” wpisuje się książka Macieja Pinkwarta (świadczy o tym rok wydania, 2016). Autor skupił się na jednym miejscu, szczególnie ulubionym przez Sienkiewicza - Zakopanem. Ale pomyliłby się ten, kto chciałby przeczytać opracowanie w systematyczny sposób wyjaśniające, dlaczego Zakopane było szczególnie istotne dla pisarza bądź uzyskać jednoznaczną odpowiedź na pytanie: co Sienkiewicz widział w Zakopanem? Co go skłaniało do ciągłych powrotów i dlaczego - czasem przewrotnie - na zmianę wychwalał i narzekał na tatrzański kurort? Książka Pinkwarta — analogicznie do przemyśleń Sienkiewicza na temat Zakopanego — jest dość przewrotna. Należy się tylko 
zastanowić czy owa przewrotność była zamierzona, czy też może przypadkowa? Jak sam autor zaznacza: „Od prawie 10 lat postuluję, by na wewnętrznym murze Starego Cmentarza zakopiańskiego wmurować niewielką tablicę upamiętniającą związki Henryka Sienkiewicza z Zakopanem [...] Jak na razie, władze miasta na wniosek ten nie odpowiadają. Więc dlatego postanowiłem napisać tę książkę". A zatem w zamierzeniach miała ona być namacalnym śladem obecności Sienkiewicza na Podhalu, a także prywatnym okazaniem buntu przez autora książki.

Publikacja składa się z dziesięciu rozdziałów, krótkiego „kalendarium” odnotowującego daty pobytu Sienkiewicza w Zakopanem oraz aneksu zawierającego listy Marii Dembowskiej do Jadwigi Janczewskiej. Zaczynając od końca: w aneksie znalazła się niezwykle interesująca korespondencja dwóch bardzo bliskich autorowi Potopu kobiet, szwagierki pisarza i przyjaciółki jego pierwszej żony. Należy pochwalić sposób przygotowania aneksu, bo choć nie jest to wydanie krytyczne, opatrzone jest szczegółowymi przypisami i potrzebnymi informacjami. Treść listów natomiast doskonale uzupełnia wiedzę na temat tego, jak bliskie osoby postrzegały Sienkiewicza, a także uwypukla wagę pobytów Sienkiewicza w Zakopanem dla ludzi mieszkających tam na stałe, takich jak Maria Dembowska. To konkretne i profesjonalne przygotowanie aneksu oraz 16 ilustracji zamieszczonych na końcu książki należy uznać za największy atut publikacji. Ilustracje „z epoki”, a także współczesne, dają (podobnie jak listy Janczewskiej i Dembowskiej) wyobrażenie o tym, jak wyglądał Sienkiewicz w czasach, gdy odwiedzał Zakopane, z kim się spotykał. Wśród fotografii znajdują się także archiwalne budynki i — jeśli było to możliwe - ich współczesne wizerunki. Dla osób, które potraktują Zakopane Henryka Sienkiewicza jako przewodnik szlakiem pisarza, fotografie na pewno będą cenną wskazówką. Aż prosi się, by w kolejnym wydaniu dołączyć do książki mapkę ułatwiającą taką wędrówkę.

Pozostaje na dłużej zatrzymać się nad kompozycją samej książki i zawartością dziesięciu części. Już na samym wstępie uwagę przykuwają tytuły rozdziałów, komponowane na wzór siedemnastowiecznej powieści Cervantesa o Don Kichocie z La Manchy, młodszym czytelnikom na pewno skojarzyłyby się z Kubusiem Puchatkiem czy Pinokiem: „Rozdział pierwszy, w którym Henryk Sienkiewicz odkrywa Amerykę i Zakopane”, „Rozdział drugi, w którym Henryk Sienkiewicz szuka domu w Zakopanem, poznaje Sabałę, nie spotyka niedźwiedzia i pakuje się na wyjazd do Ameryki”, aż po „Rozdział dziesiąty, w którym Henryk Sienkiewicz znów wędruje po Afryce, żeby zabić lwa dla dziewięcioletniej przyjaciółki, zamiast krzyża na Giewoncie spogląda na Góry Świętokrzyskie i z Alp odjeżdża jeszcze wyżej”. Niewątpliwie autor książki wykazał się dużą pomysłowością przy nadawaniu tych tytułów, jednak już sama ich treść powoduje, że czytelnik czuje się nieco zdezorientowany. Książka miała dotyczyć Zakopanego, a w nim Henryka Sienkiewicza, zaprezentowany spis treści pokazuje jednak, że spektrum zainteresowań Pinkwarta jest o wiele szersze. Potwierdza to treść książki. W każdym rozdziale można znaleźć ogromną liczbę szczegółów związanych z życiem i twórczością Sienkiewicza. Począwszy od dat dziennych, 
po informacje o wszystkich postaciach pojawiających się w kręgu autora Pana Wołodyjowskiego. Widoczna jest zarówno mocna inspiracja Kalendarzem życia i twórczości Henryka Sienkiewicza autorstwa Juliana Krzyżanowskiego, jak i ogromna wiedza autora opracowania, niewątpliwie znawcy Zakopanego i tras tatrzańskich. Wykorzystując swoją erudycję, Pinkwart weryfikuje doniesienia czy wyobrażenia o pobycie pisarza w Zakopanem, pomaga też lepiej zlokalizować miejsca zamieszkania czy przechadzek pisarza. Niezwykle interesujący jest fragment zawierający niemal detektywistyczny wywód, w którym pokazane zostało, gdzie Sienkiewicz mieszkał na pewno, a gdzie tylko prawdopodobnie, a także refleksje na temat planów zakupu domu w Zakopanem. A wszystko to na tle historii samego miasteczka i życia wielu osób mających kontakt z pisarzem. Zaproponowany kontekst jest naprawdę niezwykle szeroki, nie brak w nim takich postaci, jak choćby Modrzejewska, Chałubiński, Witkiewicz czy Chmielowski.

Jednocześnie autor Zakopanego stawia niemało pytań, pozostawiając je bez odpowiedzi, a także formułuje tezy, na które nie ma konkretnych dowodów. Wiele z nich wynika z przekonań badacza, że zamiłowanie Sienkiewicza do czytania, znajomość realiów kulturowych czy spotkanie z konkretnymi ludźmi musiało rzutować na Sienkiewicza. I trudno z tą tezą dyskutować, ale jednocześnie trudno bez szczegółowej analizy jej bronić. Taka w pewnym sensie podwójna perspektywa, z jakiej została napisana ta książka, coraz bardziej uwidacznia się z każdym kolejnym rozdziałem. Nieuważny czytelnik może zgubić się w nadmiarze szczegółów, mnogości postaci, hipotez i barwnych opowieści zakopiańskich. Sienkiewicz - choć miał być główną postacią — chwilami ginie wśród anegdot, wydarzeń pobocznych, życia innych postaci. Staje się impresją, o tyle nabierającą konkretniejszych kształtów, o ile można opowieść o jego życiu wydobyć na plan pierwszy, cytując listy pisarza, a więc oddając głos jemu samemu.

Trudno wskazać odbiorcę, dla którego książka została napisana. Bo jeśli uznać, że Zakopane Henryka Sienkiewicza pisane było z myślą o czytelniku mającym przeciętną czy nawet małą wiedzę na temat życia i twórczości pisarza, to istnieje obawa, że taki czytelnik zgubi się w tej książce jak w porannej górskiej mgle. Nie dostanie usystematyzowanej wiedzy, podanej w przystępny sposób, pomimo tego, że autor opracowania trzyma się chronologii wydarzeń. Wiele w niej takich miejsc, jak na stronie 147, gdzie autor zgromadził informacje na temat planów budowy przez Sienkiewicza domu w Zakopanem. Nie kończąc wątku, przeszedł do omówienia trudów podróży z Krakowa do Zakopanego (co samo w sobie jest niezwykle ciekawe), by w kolejnym akapicie wskazać wszystkie osoby, które w latach 1899-1911 przyjeżdżały do kurortu, nie łącząc ich jednak z pisarzem. Jeśli natomiast założyć, że autor skierował książkę do specjalistów, chcąc za jej pomocą usystematyzować wiedzę na temat kolejnego artysty mocno związanego z zakopiańską przestrzenią, to wprowadził zbyt wiele informacji oczywistych, powielanych w wielu opracowaniach. Nie zamieścił natomiast pogłębionej analizy tego, czym Zakopane było dla Sienkiewicza. Jakie tak naprawdę autor Trylogii miał związki z tym miasteczkiem i co z tego wynika dla jego twórczości czy 
przekonań estetycznych? Stąd pojawiająca się na początku recenzji hipoteza: być może Maciej Pinkwart przewrotnie sformułował tytuł swojej książki, a będący „pretekstem” do jej powstania krótki żywot Sienkiewicza w Zakopanem miał posłużyć jako punkt wyjścia do opowieści o Zakopanem — takim, jakie było w latach, gdy odwiedzał je znany pisarz? To tłumaczyłoby wprowadzenie tak wielu wątków pobocznych, a także sam tytuł: Zakopane Henryka Sienkiewicza, a więc postawienie akcentu na miejscowość, nie — pisarza.

Pomimo nadmiaru informacji i pewnego chaosu mocno dającego się we znaki przy pierwszym czytaniu książki, Zakopane Henryka Sienkiewicza należy uznać za książkę potrzebną i jeśli nawet nie wyczerpującą tematu, to z pewnością otwierającą nowe ścieżki poszukiwań, wypełnioną wieloma nowymi, interesującymi informacjami. Dla odwiedzających Zakopane na pewno spełni funkcję, którą tymczasowo przeznaczył jej autor — szczególnego zakopiańskiego znaku upamiętniającego odwiedziny autora Krzyżaków w tym kurorcie. Idealnie by było, gdyby „letnicy” (a także amatorzy zimowych wędrówek po Krupówkach), będąc w Zakopanem, zamiast kolejnej ciupagi do kolekcji, kupili książkę Macieja Pinkwarta. Bo nawet jeśli informacji w niej zbyt dużo i chwilami są one mało uporządkowane, to z całą pewnością mogą zainspirować do własnych intelektualnych poszukiwań.

Agnieszka Kuniczuk-Trzcinowicz 